Doğrudan Yabancı Yatırımlar ile Aramalı ve Sermaye Malı İthalatı Arası İlişkiler: Türkiye Ekonomisi Üzerine TodaYamamoto Nedensellik Analizleri (2005 M1-2016 M12)

\title{
Relations between Foreign Direct Investments and Intermediate and Capital Goods: Toda-Yamamoto Causality Analyses on Turkish Economy (2005 M1-2016 M12)
}

\author{
Prof. Dr. Mustafa Kemal Değer (Karadeniz Technical University, Turkey) \\ Muharrem Akın Doğanay (Karadeniz Technical University, Turkey)
}

\begin{abstract}
The aim of this study is to empirically test the relations between the FDI in Turkey's manufacturing industry and the imports of intermediate and capital goods. Monthly data for the period 2005-2016 belonging to the variables used in the study were obtained from the "Electronic Data Distribution System" of the Central Bank of the Republic of Turkey. In the determination of the period of the study, the presence of monthly data and the increase trend of the FDI coming to Turkey after 2005 have been influential. Relations between variables in the study were tried to be determined by Toda-Yamamoto causality analysis.

According to the empirical findings obtained in the study, one-way and statistically significant causal relations from FDI made in manufacturing industry to both capital goods imports and intermediate imports have been determined. However, from these relations, towards to intermediate imports is much more robust in terms of statistics.
\end{abstract}

Therefore, these findings obtained from the study shows that FDI on Turkey's manufacturing industry are an important determinant of capital goods, and especially intermediate goods imports.

\section{Giriș}

II. Dünya Savaşı sonrasında imzalanan Gümrük Tarifeleri ve Ticaret Genel Anlaşması (GATT), anlaşmaya taraf olan ülkeler arasında ticaretin serbestleşmesine hizmet ederek ticari anlamda küreselleşmenin ortaya çıkmasına yol açmıştır. Ticari küreselleşmeye 1973 yılında Bretton Woods Sistemi'nin yıkılmasıyla beraber finansal küreselleşme eşlik etmeye başlamıştır. Son yıllarda ise ekonomik anlamda küreselleşmenin bir diğer boyutu olan üretimin küreselleşmesi, Çok Uluslu Şirket (ÇUŞ)'lerin yatırım kararları ile belirgin hale gelmeye başlamıştır. Doğrudan Yabancı Yatırım (DYY)'lar olarak isimlendirilen bu tür yatırımların ortaya çıkmasında etkili olan birçok ekonomik faktör söz konusudur. Bunlar arasında yatırım yapılan ülkelerdeki işgücü ve hammadde gibi üretim faktörlerinin varlığı, vergilendirme politikalarındaki farklılıklar, ülkenin pazar büyüklüğü ve potansiyel pazarlara yakınlığ 1 gibi faktörler sayılabilir.

Öte yandan DYY'lar, yatırımın yapıldığı ülkede olumlu ve olumsuz bir takım etkilere de neden olabilmektedir. Örneğin yatırım yapılan ülkenin ekonomik büyümesini artırması, istihdam yaratması, teknoloji transferine yol açması, ihracatı teşvik etmesi ve döviz açığını kapatması gibi olumlu etkileri söz konusudur. Öte yandan ekonominin yabancıların kontrolüne girmesi, yurtiçi yatırımları caydırması, teknolojik bağımlılık yaratması, ithalat artışına yol açarak döviz ihtiyacını şiddetlendirmesi ve ekonomide ikili (dual) bir yapının oluşmasına neden olması gibi olumsuz etkileri de ortaya çıkabilmektedir. Dolayısıyla DYY'ların yatırımın yapıldığı ülke ekonomisi üzerindeki etkileri, son dönem ampirik literatürde sıklıkla ele alınan konuların başında yer almaktadır.

Bu çalışmanın amacı, Türkiye ekonomisi özelinde DYY'ların ülkenin ithalatı üzerindeki etkilerini ampirik olarak test etmektir. Bu amaç doğrultusunda çalışma 5 ana başlık altında oluşturulmuştur. Çalışmanın Giriş kısmını takiben DYY'ların diş ticaret ve özellikle de ithalat üzerindeki etkilerini ampirik olarak ele alan çalışma bulgularına yer verilmiştir. Çalışmanın üçüncü bölümünde ise veri seti ve değişkenler tanıtıldıktan sonra değişkenler arası nedensel ilişkileri belirlemeye yönelik kullanılacak yöntem verilmiştir. Çalışmanın dördüncü bölümünde elde edilen ampirik sonuçlar verildikten sonra çalışmanın son kısmında bu sonuçlar değerlendirilmeye çalışılmıştır.

\section{DYY'lar ve İthalat Üzerine Ampirik Literatür Özeti}

DYY'ların, yatırım yapıldığı ülke ekonomisi üzerindeki etkileri, günümüzde dahi hala en çok tartışılan ve ekonometrik testlerle yoğun bir şekilde ele alınan konular arasındadır. Bu kapsamda çalışmaların büyük bir kısmı, DYY'ların ekonomik büyüme üzerindeki etkileri üzerine yoğunlaşırken, bir kısım çalışmalar ise DYY'ların işsizlik ve ücretler üzerindeki etkilerini ele almışlardır. Son dönem çalışmaların bazıları ise DYY'ları dış ticaret ve ödemeler dengesi üzerindeki etkilerini inceleme konusu yapmıştır. 
Konu ile ilgili literatürde DYY'ların ticaret üzerindeki etkileri iki farklı boyutta ele alınmaktadır. Bunlardan ilki, DYY'ların ticaretin tamamlayıcısı veya ikamesi olup olmadığı konusunu ele alırken, diğer görüş ise DYY'lar ile ticaret arasındaki nedenselliğin yönü üzerine yoğunlaşmaktadır.

Ticaret teorisine göre, DYY'ların ticareti ikame edip etmediği veya tamamladığı DYY'ların motivasyonuna bağlıdır. DYY çok uluslu şirketlerin coğrafi olarak üretim aşamalarına sahip olduğu yerlerde dikeydir ve bu durumun ticareti teşvik etmesi muhtemeldir. Çokuluslu şirketlerin birden fazla yerde nihai mal ürettiği durumda ise DYY yataydır ve ticaretin yerini alması muhtemeldir. Eğer DYY, ticaretin yerini alıyorsa, yerel üretimden uzaklaşan bir dışa dönüklüğü temsil eder ve yabancıların ürettiği ürünler satılır ve ihraç edilir. Tersine, eğer DYY ticareti tamamlarsa, yerel üretim yurtdışındaki yatırımlardan faydalanır (Kıran, 2011: 150). Dolayısıyla çalışmanın bu kısmında DYY'lar ile ticaret (ihracat ve ithalat) arasındaki ilişkileri ampirik olarak ele alan çalışmaların bulgularına yer verilecektir.

\begin{tabular}{|c|c|c|c|}
\hline Yazarlar & Ülke ve Dönemi & Yöntem & Bulgular \\
\hline $\begin{array}{l}\text { Camarero \& } \\
\text { Tamarit } \\
(2003)\end{array}$ & $\begin{array}{c}\text { AB Ülkeleri, } \\
\text { ABD ve Japonya } \\
\text { (Q1.1981- Q3.1998) }\end{array}$ & $\begin{array}{r}\text { Panel Birim Kök \& } \\
\text { Eşbütünleşme Analizi }\end{array}$ & $\begin{array}{l}\text { İthalat ve ihracat ile DYY arasında } \\
\text { tamamlayıcılık ilişkisi vardır. }\end{array}$ \\
\hline $\begin{array}{l}\text { Dritsaki vd. } \\
(2004)\end{array}$ & $\begin{array}{l}\text { Yunanistan } \\
(1960-2002)\end{array}$ & $\begin{array}{c}\text { Eşbütünleşme \& } \\
\text { Granger Nedensellik } \\
\text { Analizi } \\
\end{array}$ & $\begin{array}{l}\text { Ekonomik büyüme, ithalat-ihracat ve } \\
\text { DYY, açık kapı politikası altında karşılıklı } \\
\text { olarak güçlenmektedir. }\end{array}$ \\
\hline $\begin{array}{l}\text { Kueh vd. } \\
(2007)\end{array}$ & $\begin{array}{l}\text { ASEAN-5 Ülkeleri } \\
\quad(1990-2005)\end{array}$ & ARDL Yöntemi & $\begin{array}{c}\text { DYY ve ithalat uzun vadede birbirlerini } \\
\text { tamamlayıcı nitelikte olmakla birlikte, } \\
\text { ithalat kısa vadede DYY'yi değiştirme } \\
\text { eğilimindedir. }\end{array}$ \\
\hline $\begin{array}{l}\text { Pourshahabi } \\
\text { vd. } \\
(2011)\end{array}$ & $\begin{array}{l}16 \text { Gelişmiş } \\
\text { Avrupa Ülkesi } \\
(1976-2008)\end{array}$ & $\begin{array}{c}\text { Eşbütünleşme \& } \\
\text { Granger Nedensellik } \\
\text { Analizleri }\end{array}$ & $\begin{array}{l}\text { Kisa dönemde DYY-İhracat ve DYY- } \\
\text { Itthalat arasında çift yönlü nedensellik, } \\
\text { uzun dönemde ise ithalat ve ihracattan } \\
\text { DYY'e doğru nedensellik mevcuttur. }\end{array}$ \\
\hline $\begin{array}{l}\text { Anwar \& } \\
\text { Nguyen } \\
(2011) \\
\end{array}$ & $\begin{array}{c}\text { Vietnam } \\
(1990-2007)\end{array}$ & $\begin{array}{l}\text { GLS Yöntemi } \\
\text { (Çekim Modeli } \\
\text { Yaklaşımı) }\end{array}$ & $\begin{array}{l}\text { DYY ile ihracat ve ithalat arasında } \\
\text { tamamlayıcı bir ilişki var olmaktadır. }\end{array}$ \\
\hline $\begin{array}{l}\text { Filippaios \& } \\
\text { Kottaridi } \\
(2013) \\
\end{array}$ & $\begin{array}{l}\text { Merkezi ve Doğu } \\
\text { Avrupa Ülkeleri } \\
(1992-2008)\end{array}$ & $\begin{array}{l}\text { 3SLS (Three-stage } \\
\text { Least Squares) } \\
\text { Yöntemi } \\
\end{array}$ & $\begin{array}{l}\text { DYY ithalatta olumlu bir rol } \\
\text { oynamaktadır. }\end{array}$ \\
\hline $\begin{array}{l}\text { Chani, Azam } \\
\& \text { Younas } \\
(2014) \\
\end{array}$ & $\begin{array}{c}\text { Pakistan } \\
(1972-2009)\end{array}$ & $\begin{array}{c}\text { Eşbütünleşme \& } \\
\text { Granger Nedensellik } \\
\text { Analizleri } \\
\end{array}$ & $\begin{array}{l}\text { DYY, ithalat ve ihracat arasında uzun } \\
\text { dönemde anlamlı bir ilişki vardır. }\end{array}$ \\
\hline $\begin{array}{l}\text { Tran \& Dinh } \\
\quad(2014)\end{array}$ & $\begin{array}{l}\text { Gelişmekte Olan } \\
\text { Asya Ülkeleri } \\
(1991-2011)\end{array}$ & $\begin{array}{l}\text { Panel Veri \& Zaman } \\
\text { Serisi Analizleri }\end{array}$ & $\begin{array}{l}\text { Mevcut DYY girdileri dış ticaret açığını } \\
\text { artırmakta ve ev sahibi ülke için olumsuz } \\
\text { sonuçlar doğurmaktadır. }\end{array}$ \\
\hline $\begin{array}{l}\text { Berasaluce \& } \\
\text { Romero } \\
(2015)\end{array}$ & $\begin{array}{l}\text { Güney Kore } \\
(1989-2014)\end{array}$ & $\begin{array}{c}\text { VAR, Granger } \\
\text { Nedensellik Analizleri } \\
\text { \& Block Exogeneity } \\
\text { Test }\end{array}$ & $\begin{array}{l}\text { Büyümeye dayalı ihracat hipotezinin yanı } \\
\text { sira DYY'nin ekonomik büyüme ya da } \\
\text { ihracat üzerinde herhangi bir etkisi } \\
\text { bulunmamaktadır. }\end{array}$ \\
\hline $\begin{array}{l}\text { Keho } \\
(2015)\end{array}$ & $\begin{array}{c}12 \text { Seçilmiş } \\
\text { Sahraaltı Ülkesi } \\
(1970-2013) \\
\end{array}$ & $\begin{array}{c}\text { Eşbütünleşme \& } \\
\text { Granger Nedensellik } \\
\text { Analizleri } \\
\end{array}$ & $\begin{array}{c}\text { Sonuçlar, DYY ve ihracat teşvik } \\
\text { politikaları için ampirik bir temel } \\
\text { oluşturmaktadır. }\end{array}$ \\
\hline $\begin{array}{l}\text { Napshin \& } \\
\text { Brouthers } \\
(2015)\end{array}$ & $\begin{array}{l}\text { Gelişmiş Ülkeler } \\
(2003-2006)\end{array}$ & $\begin{array}{l}\text { Siradan En Küçük } \\
\text { Kareler Regresyon } \\
\text { Yöntemi }\end{array}$ & $\begin{array}{c}\text { Gelişmiş ülkelerde DYY ve ithalat / } \\
\text { ihracat arasında daha güçlü ilişkiler vardır. } \\
\text { Ancak DYY ve ulusal ticaret dengeleri } \\
\text { arasında daha zayıf bağlantılar mevcuttur. }\end{array}$ \\
\hline $\begin{array}{l}\text { Albulescu \& } \\
\text { Goyeau } \\
(2016)\end{array}$ & $\begin{array}{l}\text { Merkezi ve Doğu } \\
\text { Avrupa Ülkeleri } \\
(2000-2013)\end{array}$ & $\begin{array}{l}\text { Rassal ve Sabit } \\
\text { Etkili Panel Veri } \\
\text { Analizleri }\end{array}$ & $\begin{array}{c}\text { Dışarıya çıkan DYY, CEE ülkelerinin } \\
\text { ticari entegrasyonunu arttırırken, } \\
\text { dışarıdan yapılan DYY'nin önemli bir etkisi } \\
\text { yoktur. }\end{array}$ \\
\hline
\end{tabular}

Tablo 1. Ampirik Literatür Özeti

Tablo 1'de verilen çalışmaların bulgularından hareketle, DYY'lar ile dış ticaret arasında evrensel bir geçerliliğe sahip bir sonuçtan bahsetmemiz mümkün değildir. Böyle bir sonucun ortaya çıkmasında çalışmalarda ele alınan ülke ve/veya ülke grubundaki farklılıklar, kullanılan yöntem ve dönemdeki farklılıklar etkilidir. Ayrıca DYY'lar ile dış ticaret arasındaki anlamlı ilişkilerin ortaya çıkmasında DYY'ların türü de (yatay veya dikey DYY) önemlidir 


\section{Veri ve Metodoloji}

$\mathrm{Bu}$ çalışmanın amacı, DYY'lar ile ticaretin ithalat boyutu arasında nedensel bir ilişsinin varlığını Türkiye ekonomisi özelinde ortaya koymaktır. Çalışmada Türkiye'ye yönelik DYY'ların çok büyük artışlar gösterdiği 2005 sonrası dönem dikkate alınmıştır. Türkiye Cumhuriyet Merkez Bankası'nın “Elektronik Veri Dağıtım Sistemi”den elde edilen aylık dolar bazlı DYY'lar ile ithalat değişkenleri, öncelikle ortalama aylık döviz kuru ile çarpılarak Türk Lirasına çevrilmiş ve daha sonra bu seriler 2003 yılı bazlı tüketici fiyat indeksi kullanılarak reelleştirilmiştir. Değişkenlere ait reel seriler, "Hareketli Ortalamalar Yöntemi” kullanılarak mevsimsellikten arındırılmıştır.

Çalışmada kullanılan değişkenler, Tablo 2'de tanımlanmıştır.

\begin{tabular}{|l|l|}
\hline Değişken & \multicolumn{1}{|c|}{ Tanım } \\
\hline RIMLDYY & Reel İmalat Sanayindeki Doğrudan Yabancı Yatırımlar \\
RTOPDYY & Reel Toplam Doğrudan Yabancı Yatırımlar \\
RSERITH & Reel Sermaye Malı İthalatı \\
RARAITH & Reel Ara Malı İthalatı \\
RTOPITH & Reel Toplam Mal İthalatı \\
\hline
\end{tabular}

Tablo 2. Çalışmada Kullanılan Değişkenlerin Kısaltma ve Açılımları

Çalışmada 2005 M1-2016 M12 dönemi verileri kullanılarak değişkenler arası nedensel ilişkiler Toda ve Yamamoto nedensellik analizi ile belirlenmeye çalışılmıştır. Toda ve Yamamoto nedensellik analizleri aşağıdaki gibi tanımlanan eşitlik kullanılarak gerçekleştirilmiştir.

Toda ve Yamamoto (1995) nedensellik sınaması yaklaşımı, değişkenlerin seviye değerlerinin yer aldığ Vektör Otoregressif (VAR) modeli üzerinden gerçekleştirilir. VAR modelinin optimal gecikme uzunluğu (k) ve değişkenlerin en büyük durağanlık seviyesi olan maksimum bütünleşme derecesi $\left(\mathrm{d}_{\max }\right)$ belirlenerek, VAR sistemi aşağıdaki gibi tanımlanan eşitliklerle tahmin edilir (Tandoğan ve Genç, 2016: 66).

$$
\begin{aligned}
& X_{t}=\emptyset_{0}+\sum_{i=1}^{k} \gamma_{1 i} X_{t-i}+\sum_{i=k+1}^{k+d_{\max }} \gamma_{2 i} X_{t-i}+\sum_{i=1}^{k} \beta_{1 i} Y_{t-i}+\sum_{i=k+1}^{k+d_{\max }} \beta_{2 i} Y_{t-i}+E_{1 t} \\
& Y_{t}=\tau_{0}+\sum_{i=1}^{k} \sigma_{1 i} Y_{t-i}+\sum_{i=k+1}^{k+d_{\max }} \sigma_{2 i} Y_{t-i}+\sum_{i=1}^{k} \delta_{1 i} X_{t-i}+\sum_{i=k+1}^{k+d_{\max }} \delta_{2 i} X_{t-i}+E_{2 t}
\end{aligned}
$$

\section{Ampirik Bulgular}

Çalışmada nedensellik sınamaları yapılmadan önce değişkenlere ait tanımlayıcı istatistikler ile korelasyon matrisi, Tablo 3 ve Tablo 4'te sunulmuştur.

\subsection{Tanımlayıcı İstatistikler ve Korelasyon Matrisi}

\begin{tabular}{|l|c|c|c|c|c|}
\hline Değişkenler & RIMLDYY & RTOPDYY & RSERITH & RARAITH & RTOPITH \\
\hline Ortalama & 207.425 & 894.840 & 2372.749 & 10831.090 & 15115.250 \\
\hline Ortanca & 119.148 & 573.474 & 2296.726 & 11106.580 & 15371.310 \\
\hline Maksimum & 1782.191 & 7264.261 & 4225.708 & 14826.810 & 20810.930 \\
\hline Minimum & 12.666 & 51.727 & 1190.758 & 6388.344 & 8533.777 \\
\hline Standart Sapma & 279.886 & 1031.147 & 566.773 & 2206.615 & 3066.746 \\
\hline Gözlem Sayıs1 & 143 & 143 & 143 & 143 & 143 \\
\hline
\end{tabular}

Tablo 3. Tanımlayıcı İstatistikler ve Korelasyon Matrisi

Tablo 3'de yer alan bilgilere göre Türkiye'de 2005M1-2016M12 döneminde yapılan RIMLDYY, ortalama olarak 207 Milyon TL kadar iken, ortalama RTOPDYY yaklaşık 895 Milyon TL olarak gerçekleşmiştir. En yüksek olduğu dönemde ise 7.264 Milyon TL seviyesine ulaşmıştır. Belirtilen dönemde ortalama RSERITH 2.372 Milyon TL olurken, RARAITH ortalama olarak aylık 10.831 Milyon TL olmuştur. Ayrıca RTOPITH 15.115 Milyon TL ortalamaya sahiptir.

Çalışmada kullanılan veriler ile ilgili bu genel görünümün yanında değişkenler arası ikili ilişsileri veren korelasyon katsayıları, Tablo 4'te sunulmuştur. 


\begin{tabular}{|c|c|c|c|c|c|}
\hline Olasılık & LRIMLDYY & LRTOPDYY & LRSERITH & LRARAITH & LRTOPITH \\
\hline \multirow{2}{*}{ LRIMLDYY } & 1.000 & & & & \\
\hline & ----- & & & & \\
\hline \multirow{2}{*}{ LRTOPDYY } & 0.496 & 1.000 & & & \\
\hline & $(0.000)$ & ----- & & & \\
\hline \multirow{2}{*}{ LRSERITH } & 0.213 & 0.160 & 1.000 & & \\
\hline & $(0.011)$ & $(0.056)$ & ----- & & \\
\hline \multirow{2}{*}{ LRARAITH } & 0.336 & 0.237 & 0.818 & 1.000 & \\
\hline & $(0.000)$ & $(0.004)$ & $(0.000)$ & ----- & \\
\hline \multirow{2}{*}{ LRTOPITH } & 0.310 & 0.212 & 0.893 & 0.987 & 1.000 \\
\hline & $(0.000)$ & $(0.011)$ & $(0.000)$ & $(0.000)$ & ----- \\
\hline
\end{tabular}

Tablo 4. Tanımlayıc İstatistikler ve Korelasyon Matrisi

Not: Korelasyon analizi için reel serilere uyarlanan mevsimsel düzeltmeden sonra logaritmaları (L) alınmıştır.

Tablo 5'de verilen korelasyon katsayıları ise değişkenler arasında pozitif ve anlamlı ilişkinin varlığına işaret etmektedir.

\subsection{Toda ve Yamamoto Nedensellik Analizi Sonuçları}

Çalışmada nedensellik analizlerine geçmeden önce değişkenlerin durağanlık sınamaları ADF yöntemi ile gerçekleştirilmiş ve sonuçlar Tablo 5'de verilmiştir.

\begin{tabular}{|c|c|c|c|c|c|}
\hline \multirow[b]{2}{*}{ Değişkenler } & LRIMLFDI & LRTOPFDI & LRSERITH & LRARAITH & LRTOPITH \\
\hline & $\mathrm{t}$ istatistiği & $\mathrm{t}$ istatistiği & $\mathrm{t}$ istatistiği & $\mathrm{t}$ istatistiği & $\mathrm{t}$ istatistiği \\
\hline Seviye & $-4.353 *$ & $-3.547 * *$ & -2.265 & -2.825 & -2.492 \\
\hline \multirow[b]{2}{*}{ Değişkenler } & DLRIMLFDI & $\Delta$ LRTOPFDI & DLRSERITH & DLRARAITH & $\triangle$ LRTOPITH \\
\hline & $\mathrm{t}$ istatistiğ $\mathrm{i}$ & $\mathrm{t}$ istatistiği & $\mathrm{t}$ istatistiği & $\mathrm{t}$ istatistiği & $\mathrm{t}$ istatistiğ $\mathrm{i}$ \\
\hline Birinci Fark & $-15.947 *$ & $-11.467 *$ & $-13.064 *$ & $-17.572 *$ & $-19.359 *$ \\
\hline
\end{tabular}

Tablo 5. ADF Birim Kök Sinama Sonuçlarl (Sabitli ve Trendli)

Not: *, **ve *** sırasıyla \%1, \%5 ve \%10'da istatistiki açıdan anlamlılığı ve $\Delta$ ise serilerin birinci farkını ifade etmektedir.

Tablo 5'deki ADF Birim Kök sınamaları sonuçlarına göre TOPDYY ile IMLDYY değişkenleri seviyesinde durağan iken, ARAITH, SERITH ve TOPITH değişkenleri ise seviyesinde durağan değildir. Değişkenlerin birinci farkları alındığında ise tüm serilerin I(1)'de durağan hale geldiği görülmektedir. Dolayısıyla çalışmada farklı seviyelerde durağan hale gelen değişkenleri kullanarak nedensellik analizlerini gerçekleştirmeye imkân veren Toda ve Yamamoto nedensellik analizleri, aşağıdaki eşitlikleri kullanarak yapılmıştır.

Tablo 6, Toda ve Yamamoto nedensellik analizi sonuçlarını göstermektedir. 


\begin{tabular}{|c|c|c|c|c|c|c|c|}
\hline \multicolumn{8}{|c|}{$\operatorname{VAR}(4) \mathrm{k}=3, \mathrm{dmax}=1$} \\
\hline \multicolumn{4}{|c|}{ Bağımlı Değişken: LRIMLDYYSA } & \multicolumn{4}{|c|}{ Bağımlı Değişken: LRSERITHSA } \\
\hline Bağımsız Değişken & Ki-kare & df & Olasilik & Bağımsız Değişken & Ki-kare & $\mathrm{df}$ & Olasıl1k \\
\hline LRSERITHSA & 4.599 .352 & 3 & 0.2036 & LRIMLDYYSA & 6.429 .202 & 3 & 0.0925 \\
\hline \multicolumn{8}{|c|}{$\operatorname{VAR}(3) \mathrm{k}=2, \mathrm{dmax}=1$} \\
\hline \multicolumn{4}{|c|}{ Bağımlı Değișken: LRIMLDYYSA } & \multicolumn{4}{|c|}{ Bağımlı Değişken: LRARAITHSA } \\
\hline Bağımsız Değişken & Ki-kare & df & Olasılık & Bağımsız Değişken & Ki-kare & $\mathrm{df}$ & Olasıl1k \\
\hline LRARAITHSA & 0.753302 & 2 & 0.6862 & LRIMLDYYSA & 712.886 & 2 & 0.0283 \\
\hline \multicolumn{8}{|c|}{$\operatorname{VAR}(3) \mathrm{k}=2, \mathrm{dmax}=1$} \\
\hline \multicolumn{4}{|c|}{ Bağımlı Değișken: LRIMLDYYSA } & \multicolumn{4}{|c|}{ Bağımlı Değişken: LRTOPITHSA } \\
\hline Bağımsız Değişken & Ki-kare & df & Olasılık & Bağımsız Değişken & Ki-kare & $\mathrm{df}$ & Olasılık \\
\hline LRTOPITHSA & 0.452004 & 2 & 0.7977 & LRIMLDYYSA & 9.842 .969 & 2 & 0.0073 \\
\hline \multicolumn{8}{|c|}{$\operatorname{VAR}(6) \mathrm{k}=5, \mathrm{dmax}=1$} \\
\hline \multicolumn{4}{|c|}{ Bağımlı Değișken: LRTOPDYYSA } & \multicolumn{4}{|c|}{ Bağımlı Değişken: LRSERITHSA } \\
\hline Bağımsız Değişken & Ki-kare & $\mathrm{df}$ & Olasılık & Bağımsız Değişken & Ki-kare & $\mathrm{df}$ & Olasılık \\
\hline LRSERITHSA & 9.692 .734 & 5 & 0.0844 & LRTOPDYYSA & 1.241 .797 & 5 & 0.0295 \\
\hline \multicolumn{8}{|c|}{$\operatorname{VAR}(3) \mathrm{k}=2, \mathrm{dmax}=1$} \\
\hline \multicolumn{4}{|c|}{ Bağımlı Değişken: LRTOPDYYSA } & \multicolumn{4}{|c|}{ Bağımlı Değişken: LRARAITHSA } \\
\hline Bağımsız Değişken & Ki-kare & df & Olasılık & Bağımsız Değişken & Ki-kare & $\mathrm{df}$ & Olasılık \\
\hline LRARAITHSA & 388.353 & 2 & 0.1435 & LRTOPDYYSA & 4.714 .841 & 2 & 0.0947 \\
\hline \multicolumn{8}{|c|}{$\operatorname{VAR}(3) \mathrm{k}=2, \mathrm{dmax}=1$} \\
\hline \multicolumn{4}{|c|}{ Bağımlı Değișken: LRTOPDYYSA } & \multicolumn{4}{|c|}{ Bağımlı Değișken: LRTOPITHSA } \\
\hline Bağımsız Değişken & Ki-kare & df & Olasilık & Bağımsız Değişken & Ki-kare & $\mathrm{df}$ & Olasılık \\
\hline LRTOPITHSA & 3.481 .395 & 2 & 0.1754 & LRTOPDYYSA & 5.358 .214 & 2 & 0.0686 \\
\hline
\end{tabular}

Tablo 6. Nedensellik Analizi Sonuçları

Tablo 6'da verilen ampirik bulgulara göre imalat sanayi DYY'larından toplam, aramalı ve sermaye malı ithalatına doğru tek yönlü nedensel ilişkiler mevcut iken, bu ilişkiler içerisinde istatistiki olarak en güçlü olanı, toplam ithalata doğru olanıdır. Diğer taraftan toplam DYY'lar ile sermaye malı ithalatı arasında iki yönlü ve toplam DYY'lardan toplam ve aramalı ithalatına doğru ise tek yönlü nedensel ilişkiler söz konusudur.

\section{Sonuç ve Değerlendirme}

DYY'ların nedenleri ve sonuçları hakkında tartışmalar, son yıllarda giderek artmaya ve çeşitlenmeye başlanmıştır. Bu kapsamda DYY'ların nedenlerini araştıran “Tekel Üstünlüğü Teorisi”, "Oligopolcü Tepki Teorisi”, "İçselleştirme Teorisi” ve "OLI Teorisi” gibi son zamanlarda ortaya çıkmaya başlamıştır. Aynı şekilde DYY'ların yatırımın yapıldığı ülke ekonomisi üzerinde etkilerini ele alan bir kısım çalışmalar DYY'ların olumlu etkilerine dikkatleri çekerken, diğer bir kısım çalışmalar ise DYY'ların olumsuz etkilerini dile getirmektedir. DYY'ların olumlu etkileri arasında sermaye malı ithalatına yol açarak ülkeye yeni teknoloji ve yönetim bilgisinin transferine imkan vermesi yer alırken, olumsuz etkileri arasında ise aramalı ve sermaye malı ithalatını uyararak döviz giderlerini artırma ve teknolojik bağımlılık yaratma gibi etkilerinden bahsedilebilir. Dış ticaret ve özelde de ithalat üzerinde DYY'ların etkilerine yönelik bu tezat açıklamaların her ikisi de kendi içlerinde haklılık payına sahiptir. Dolayısıyla DYY'ları ticaret üzerindeki net etkisi, birbirine ters etkilerin hangisinin büyük olacağına bağlıdır. DYY'ların dış ticaret üzerinde özellikle de aramalı ve sermaye malı ithalatı üzerindeki etkileri her şeyden önce DYY'ların türüne ve niteliğine bağlı olacaktır.

Bu çalışmanın amacı, 2005 yılı sonrası büyük miktarda DYY çekebilen fakat son yıllarda ise bu özelliğini kaybeden Türkiye'de DYY'lar ile aramalı ve sermaye malı ithalatı arasındaki ilişkileri ampirik olarak belirlemektir. Bu kapsamda 2005-2016 dönemi aylık verileri dikkate alınarak, hem imalat sanayine yönelen DYY'lar, hem de toplam DYY'lar ile ithalat arası ilişkiler, Toda ve Yamamoto nedensellik analizleri yardımıyla inceleme konusu yapılmıştır. Çalışmada yapılan analizlerden elde edilen bulgulara göre imalat sanayi DYY'larından toplam, aramalı ve sermaye malı ithalatına doğru tek yönlü nedensel ilişkiler mevcut iken, toplam DYY'lar ile sermaye malı ithalatı arasında iki yönlü, aramalı ve toplam mal ithalatı ile ise tek yönlü nedensellikler söz konudur. Çalışmada elde edilen bu bulgular, Türkiye'deki DYY'ların ülkenin döviz ihtiyaçlarını artırarak ithalat üzerinde uyarıcı etkilere neden olduğuna işaret etmektedir. Ayrıca DYY'lardan sermaye malı ithalatına doğru nedensel ilişkilere dair bulgular ise DYY'ların ülkeye yeni teknoloji transferine imkan verdiği şeklinde yorumlanabilir. 
Sonuç olarak DYY'ların Türkiye'de sermaye malı ithalatına yol açarak, yeni teknolojilerin ülke ekonomisine kazandırması önemli bir etki iken, bu yatırımların ihtiyaç duyduğu aramalı niteliğindeki girdilerin ithal edilen alternatiflerinin yurtiçi pazarlardan temin edilmesi DYY'ların olumlu etkilerinin daha da artmasına yol açacaktır. Dolayısıyla küreselleşme süreci ile birlikte dünya ekonomisine entegre olan Türkiye'de DYY'ların miktarını artıracak ve bu yatırımların özellikle imalat sanayi sektörlerine yönelmesini sağlayacak sanayi ve teşvik politikalarına ihtiyaç duyulmaktadır. Bununla birlikte son yıllarda Türkiye ekonomisine yönelen yatırımların ağırlıkla "Bankacılık ve Finans” sektörleri ile "Gayri Menkul” sektörlerinde yoğunlaştığı gerçeği, DYY'ların ülke ekonomisine olumlu katkıları konusunda endişelere de yol açmaktadır. Bu nedenle DYY'ların imalat sanayini hedef alan yatırımlar olarak gerçekleşmesinin ülke ekonomisine katkılara çok daha fazla olacaktır.

\section{Kaynakça}

- $\quad$ Albulescu, C. T., \& Goyeau, D. (2016). The Interaction between Trade and FDI: the CEE Countries Experience (No. hal-01361954).

- Anwar, S., \& Nguyen, L. P. (2011). "Foreign Direct Investment and Trade: The Case of Vietnam", Research in International Business and Finance, 25(1), 39-52.

- $\quad$ Berasaluce, J., \& Romero, J. (2015). "Exports, Imports, FDI and GDP in the Republic of Korea: 19802014”, (No. 2015-06), El Colegio de México, Centro de Estudios Económicos.

- Camarero, M., \& Tamarit, C. (2004). "Estimating the Export and Import Demand for Manufactured Goods: The Role of FDI", Review of World Economics/Weltwirtschaftliches Archiv, 347-375.

- Chani, M. I., Azam, M., \& Younas, A. (2014). "The Causal Relationship between Foreign Direct Investment, Imports and Exports in Pakistan”, Bulletin of Business and Economics (BBE), 3(3), 142-149.

- $\quad$ Dritsaki, M., Dritsaki, C., \& Adamopoulos, A. (2004). “A Causal Relationship between Trade, Foreign Direct Investment and Economic Growth for Greece”, American Journal of Applied Sciences, 1(3), 230-235.

- Filippaios, F., \& Kottaridi, C. (2013). “Complements or Substitutes? New Theoretical Considerations and Empirical Evidence on the Imports and inward FDI Relationship in Central and Eastern European Countries", International Review of Applied Economics, 27(6), 766-797.

- Hsiao, F. S., \& Hsiao, M. C. W. (2006). "FDI, Exports, and GDP in East and Southeast Asia-Panel Data versus Time-Series Causality Analyses", Journal of Asian Economics, 17(6), 1082-1106.

- Keho, Y. (2015). "Foreign Direct Investment, Exports and Economic Growth: Some African Evidence”, Journal of Applied Economics \& Business Research, 5(4), 209-220.

- Kiran, B. (2011). “Causal Links between Foreign Direct Investment and Trade in Turkey”, International Journal of Economics and Finance, 3(2), 150-158.

- $\quad$ Kueh, J., Puah, C. H., Lau, E., \& Abu Mansor, S. (2007). "FDI-Trade Nexus: Empirical Analysis on ASEAN-5", University Library of Munich, Germany.

- Napshin, S., \& Brouthers, L. E. (2015). "Intermediary Products: FDI Strategies, Imports, Exports, and Trade Balances in Developed Economies”, Thunderbird International Business Review, 57(4), 311-322.

- Pourshahabi, F., Salimi Soderjani, E., \& Mahmoudinia, D. (2011). "Panel Causality Relationship among FDI and Trade (Evidence from 16 Advanced Europe Countries)", Iranian Economic Review, 17(1), 115-133.

- Tandoğan, D., \& Genç, M. C. (2016). “Türkiye'de Turizm ve Ticari Açıklık Arasındaki İlişki: Toda ve Yamamoto Nedensellik Yaklaşımı”, AİB̈̈-IIIBF Ekonomik ve Sosyal Araştırmalar Dergisi, 12(1), 59-70.

- $\quad$ Toda, H. Y., \& Yamamoto, T. (1995). "Statistical Inference in Vector Autoregressions with Possibly Integrated Processes", Journal of Econometrics, 66(1), 225-250.

- $\quad$ Tran, T. A. D., \& Dinh, T. T. B. (2014). "FDI Inflows and Trade Imbalances: Evidence from Developing Asia", The European Journal of Comparative Economics, 11(1), 147. 